\title{
Impact of ADR Listing on the Trading Volume and Volatility in the Domestic Market
}

\author{
Demissew Diro Ejara \\ William Paterson University of New Jersey, U.S.A. \\ Chinmoy Ghosh \\ University of Connecticut, U.S.A.
}

This paper investigates the impact of ADR listing on the trading volume and volatility of the domestic market. Existing theories indicate that trading shifts to a market with lower transaction costs, and the level of volatility is directly related to the level of trading activity. The analyses provide empirical evidence showing increase in both trading volume and price volatility in the domestic market after ADR listing. The increase in volatility is attributed to noise resulting from public information as opposed to from increased trading friction. This suggests improvement in liquidity following ADR listing. Comparison across country groups indicates marginally higher gain for emerging market stocks although the difference is not statistically significant. Auction type markets gain more in terms of increase in trading volume than dealer type markets (JEL: G15, N20).

Keywords: ADR, cross listing, market segmentation, market liquidity., transparency.

\section{Introduction}

Capital markets around the globe are being increasingly liberalized. Liberalization usually does away with capital controls, foreign ownership restrictions of domestic companies, and entry restrictions to foreign traders in the domestic capital markets. A stream of literature explores the impact of liberalization on the financial integration of

* The paper is based on a part of Ejara's dissertation at University of Connecticut. We thank an anonymous referee, Ken Nunn and seminar participants at the University of Connecticut, Storrs, University of Massachusetts, Boston, 1999 European Financial Management Association meetings at Helsinki, Finland and Financial Management Association Meeting at Orlando, FL. for their comments and suggestions.

(Multinational Finance Journal, 2004, vol. 8, no. 3 \& 4, pp. 247-274)

(C) Multinational Finance Society, a nonprofit corporation. All rights reserved. DOI: $10.17578 / 8-3 / 4-5$ 
capital markets. ${ }^{1}$ In financially integrated markets, financial assets with related risk characteristics have similar expected returns. Goldberg and Delgado (2001) use data on individual stocks to examine the financial integration of Latin America versus South Asian companies. They demonstrate that Argentina, Chile, Mexico and Thailand's stock markets are financially integrated. In general, the stocks in integrated countries become more correlated with world and industry indexes, and mean returns for these stocks decrease and become more aligned with the mean returns of their respective industry indexes. Niarchos et al. (1999) investigate the information transmission between the U.S. and Greek stock markets. Their tests reveal no spillover between these two markets for the conditional mean and variance, and fail to detect any common trend in the movement of these markets. They conclude that U.S. and Greek markets are not integrated.

An important way to facilitate liberalization is the issuance of American Depositary Receipts (ADR). ADRs are negotiable instruments representing foreign securities. ADRs trade on US stock exchanges, in US dollars. In addition to facilitating foreign ownership of domestic companies, issuance of ADRs opens an alternate trading venue for the securities of the companies. The ADRs trade on US exchanges while the underlying shares trade in the domestic markets.

An important benefit of the availability of alternative trading venue is to enable and encourage foreign traders to participate in the local market thereby increasing liquidity of the stock. Increase in liquidity attracts foreign information traders and analysts, which in turn increases the precision of price information, and reduces volatility in the domestic market. According to Domowitz et al. (1997), hereafter called DGM, such improvement in market quality depends on the degree of quotation transparency between the U.S. market and the domestic market. ${ }^{2}$ DGM argue that, "If inter-market information is freely available, cross-listing results in improvement in market quality....In the opposite case, where inter-market information linkages are extremely poor, cross-listing reduces liquidity and increases volatility in the local market."

This study has two objectives. First is the analysis of the impact of ADR listing on the liquidity and volatility of trading in the domestic

1. Levine and Zervos (1996) discuss the impact of liberalization on the capital market in the emerging countries in more detail.

2. Quotation transparency refers to the degree of information linkage between the US and domestic capital markets. 
shares of the foreign firm. Previous studies by DGM and Hargis (1996) provide evidence that after ADR listing, average daily trading volume increases in the domestic market. These studies, however, report mixed results on the impact of ADR listing on volatility of the domestic shares. The analysis in DGM and Hargis (1996) is extended by expanding the sample to include ADRs from Africa, Asia, Europe and Latin America. The DGM study is limited to 25 ADRs issued by 16 Mexican companies. Hargis (1996) is based on 65 ADRs by four Latin American countries (Argentina, Brazil, Chile and Mexico). Including ADRs from Africa, Asia and Europe provides an opportunity to examine the impact of inter-country differences in information transmission on liquidity and volatility of trading in the domestic market. Conceivably, inter market information linkage between the U.S. market and other developed markets are relatively more transparent than that between the U.S. market and emerging markets. Finally, the impact of increase in total trading time resulting from ADR listing for countries in different time zones is explored. Increase in trading time increases the flow of public and private information into the market, which in turn increases volatility; see Makhija and Nachtmann (1990).

The issue of the impact of ADR listing on U.S. exchanges on the standard measures of market quality in the domestic market is especially important to the investors and corporations of emerging markets. It is equally important to the policy makers in those countries since there is concern that ADR listing may cause shift in trading from domestic capital markets to the more liquid U.S. capital markets. There is compelling evidence that ADR listing reduces cost of capital. ${ }^{3}$ But the effect on volatility, trading volume, and migration of traders from the domestic to the ADR market remains unresolved. Does the effect vary across countries, or across U.S. exchanges? Is the overlap of trading time between the domestic and U.S. market materially important?

The remainder of the paper proceeds as follows. The next section

3. Miller (1999) shows that announcements of ADR listing decisions are associated with significantly positive valuation effects in the stocks in the domestic market. Miller attributes his results to relaxation of international trading barriers. Hertzel et al. (2000) examine the impact on prices of German stocks in the home market around the filing, announcement, and listing of German ADRs. They find that filing of reports in accordance with U.S. GAAP is associated with positive abnormal returns, announcement period returns are mixed, and listing elicits positive abnormal returns. Recently, Cantale (1998) and Fuerts (1998) develop models to demonstrate that management signals its quality by listing on stricter exchanges and that listing on stricter exchanges increases shareholder wealth because it reduces private benefits from control. 
provides a brief introduction to ADRs, the specifics of different ADR programs, and their trading mechanisms. Section III presents a discussion of theoretical and empirical literature on the subject. Section IV describes the sample and data. Section V presents the method of analyses and results. Section VI concludes.

\section{American Depositary Receipts (ADRs)}

ADRs facilitate the trading of shares by foreign companies in the U.S. capital market. A trustee holds shares underlying the ADRs in the domestic market, and receipts are issued in the U.S. market by a depository bank (Bank of New York, Citibank, etc.). These receipts, called ADRs, are treated as negotiable instruments representing foreign company shares and trade in U.S. dollars in the U.S. capital market. ${ }^{4}$

A sponsored ADR program is initiated by the issuing company to raise capital, increase liquidity of shares, and achieve broader dispersion of ownership. In these programs, a single depository handles the investor relations activities including clearance, settlement, transfer, and ownership changes. The issuing company pays all costs associated with these activities. A non-sponsored ADR is initiated by the depository bank to meet U.S. investors' demand for foreign company shares. As of November 1996, 1,687 ADRs (1,315 sponsored and 372 non-sponsored) are trading in the U.S. 1,067 (775 sponsored) of which are from developed countries, while emerging markets account for the remaining 620 (540 sponsored) cases. ${ }^{5}$

ADR programs fall in four main categories depending on purpose, trading locale, and listing requirements. Level I ADRs are traded in the Over the Counter Market (OTC) or on the Pink Sheet and do not require SEC approval or compliance with U.S. Generally Accepted Accounting Principles (GAAP). Being the most convenient and least expensive way to enter the U.S. market, Level I ADRs comprise the largest and most rapidly growing group with more than 1,000 cases. Level II ADRs are traded on major exchanges (NYSE, AMEX, and NASDAQ) and require full SEC disclosure and compliance with U.S. GAAP. For levels I and II ADRs, no new shares are issued; rather, shares are purchased by the

4. For a detailed discussion of American Depositary Receipts; see Pulatkonak and Sofianos (1999) and Hertzel et al. (2000).

5. Source: Bank of New York and Citibank. 
broker in the foreign market, deposited with the custodian bank, and ADRs are issued in exchange in a fixed ratio. Level III ADRs are for raising capital. Traded on major exchanges (NYSE, AMEX, and NASDAQ), they must comply with full SEC disclosure and U.S. GAAP requirements. Companies issuing Level III ADRs either go public for the first time or are public companies in their home countries.

\section{Related Literature and Hypotheses}

Can two markets co-exist simultaneously for the same security or does one market dominate the other? Pagano (1989) develops a model to explore the impact of number of traders and the variance (diversity) of traders' endowment on expected utility of agents' terminal wealth. He demonstrates that expected utility of terminal wealth decreases with the variance of the price at which the stock can be traded. Higher variance of prices provides more opportunities of buying low and selling high resulting in potentially high speculative profits. Under this scenario, a larger number of traders-which implies less variation in average endowment, and therefore in market prices-entails lower expected profits. Pagano denotes this "speculative value". Alternatively, lower variation in endowment and a larger number of traders in the market provide greater liquidity value.

Pagano shows that when traders can choose between two markets where a stock trades simultaneously, the choice reflects differential transaction costs, and the offsetting effects of speculative and liquidity values. If trading is costless or cost the same in both markets, then equilibrium implies that the markets can coexist if they are identical in the number of traders and the distribution of their equity endowments. But, this equilibrium is not sustainable under the slightest disturbance, and all traders will migrate to only one market. With differential trading costs, two markets can coexist if (1) the distribution of traders' endowment is more diverse in one market; or (2) one market has both greater diversity of endowment (higher speculative value) and more traders (higher liquidity value). In either case, higher transaction costs in the otherwise favorable market prevent all trading from concentrating there. In essence, the greater variance of equity endowment provides greater depth and higher speculative value, and compensates for the higher transaction cost.

Pagano's proposition implies that for companies listing ADRs in the 
U.S. market, unless the domestic market has greater diversity of endowment to offer higher speculative value, and/or attract more liquidity traders following ADR listing, trading shifts to the U.S. market where transaction cost is lower.

DGM derive a model where the probability of a trade is a decreasing function of bid-ask spread, and the information content of a trade is an increasing function of bid-ask spread. Intuitively, probability of a trade and hence trading intensity increases as bid-ask spread decreases. As trading intensity increases, market liquidity improves so that information content or the price impact of each trade decreases, and vice versa. In this framework, the variance of successive changes in closing prices can be broken down into two components. The first component, referred to as base level volatility, captures the variance due to bid-ask bounce and the asymmetry of overnight price information. Increased trading frequency reduces bid-ask bounce, and increase in the number of traders improves price information. In essence, base level volatility is an inverse function of the number of traders in the market. The second component, referred to as volatility due to trading friction, depends on expected daily trading volume through a factor, which is a decreasing function of market liquidity. Measured as the inverse of the price impact of a given order imbalance, market liquidity is a decreasing function of bid-ask spread, and therefore positively related to trading frequency, or number of traders. Therefore, increase in number of traders reduces price volatility through the second component as well. ${ }^{6}$

DGM posit that the effect of ADR listing on liquidity and volatility in the domestic market depends on the degree of "quotation transparency" between the domestic and the U.S. markets. For ADRs, "quotation transparency" reflects the extent to which price information in the domestic and the U.S. markets is observable. With perfect quotation transparency, information on prices and quotes in both markets is freely available at all times. If the cost of trading ADRs in the U.S. market is less than that in the domestic market for some investors then these investors who would otherwise not trade are induced to trade in the U.S. market after ADR listing. This increases total number of traders in the two markets. The resulting improvement in trading frequency reduces bid-ask spread, and enhances market liquidity. The

6. This result is clearly contradictory to the predictions to Pagano's model wherein an increase in price volatility improves the potential for trading profits. The contradiction is attributable to Pagano's assumption that all traders are speculators. As he notes in footnote 4 (p. 260), liquidity traders would lose from an increase in price volatility. 
combined effect of these factors is to reduce volatility, and increase expected trading volume. Under perfect quotation transparency (complete integration), both markets are impacted favorably, although the distribution of volume may depend on the relative transaction costs.

If the markets are not informationally linked (zero quotation transparency between the two markets, complete fragmentation), foreign traders and possibly some local traders for whom trading costs are lower in the U.S. market will migrate to the ADR market, but no new traders will enter the domestic market. Although new traders may enter the ADR market increasing overall trading volume, the decrease in trading activity in the domestic market increases bid-ask spread and volatility, and reduces liquidity and trading volume.

Overall, the impact on market quality, bid-ask spread, and volatility in the domestic market following ADR listing reflects the interaction of relative trading costs, and the degree of integration between the markets. DGM study twenty-five Mexican stocks after they list ADRs in the U.S. market. For fifteen of these, they find an increase in average daily trading volume in the domestic market after ADR listing. Standard deviation of daily price changes increases in twenty-two stocks, and decreases in two. Consistent with the hypothesis that volatility may increase after ADR listing both because of increase in base level volatility and in volatility due to trading friction, their analyses show increase in base level volatility for twenty-one stocks, and increase in volatility related to trading volume for fourteen of them.

In a related study involving sixty-five companies from four Latin American countries, Hargis (1996) finds an increase in trading volume in the domestic market after ADR listing for fifty of them. Using an approach similar to DGM's, Hargis reports decrease in base level volatility for seventeen stocks in a sub-sample of twenty-six stocks, and decrease in volatility related to trading volume for eighteen of them. These results indicate an improvement in liquidity after ADR listing, and are consistent with Merton's (1987) model, which shows positive relation between ownership dispersion and stock's liquidity.

Bloomfield and O'Hara (2000) argue that low-transparency dealer can capture early order flows than high-transparency dealers. Subsequently, the low-transparency dealers can use their informational advantage, quote narrower spreads and earn more profit than high-transparency dealers. In an experimental setting, they test the above proposition and find results that support it. They also find that most dealers choose to be of low-transparency and the high- 
transparency dealers will exist and being a sole transparent dealer is sometimes advantageous. The implication of their finding in the ADR setting is dealers may prefer to trade in the home country market, which in general are less transparent than U.S. markets. The low transparency and greater spread in the home country enables dealers to make greater profits. This may increase trading activity in the home country. Bloomfield and O'Hara and O'Hara (1999) further state that some information traders prefer to send their orders to a non-transparent market (dealer) to hide their trades. Sometimes they send false trading signal to the transparent market and actually trade in the non-transparent market. This also tends to favor the argument that trading activity increases in the home country after ADR listing.

\section{Sample and Data}

The sample includes one hundred and fifty-three companies that issued ADRs between December 1994 and July 1997 for which sufficient daily trading data are available before and after ADR listing. The data were collected from the lists of ADRs from Bank of New York, Citibank, and JP Morgan, and cross-referenced with the list of foreign companies trading on the NYSE, AMEX, NASDAQ, and Over the Counter (OTC) markets. ${ }^{7}$ These companies represent twenty-three different countries. Fifty-six companies are from nine emerging markets (China, Indonesia, Korea, Mexico, Philippines, Portugal, South Africa, Singapore and Taiwan) and the remaining ninety-seven are from fourteen developed countries (Australia, Austria, Finland, France, Germany, Hong Kong, Japan, Netherlands, New Zealand, Norway, Spain, Sweden, Switzerland, and UK). The country with the largest number of ADRs in the sample is Hong Kong with thirty-three stocks. Twelve ADRs each trade on NYSE and NASDAQ. One hundred and three ADRs are Level 1, which trade in the OTC market, and twenty-six ADRs trade on the Portal (Rule 144A ADRs). ${ }^{8}$

7. The Level I ADRs trade in the Over the Counter Market (OTC) or on the Pink Sheet and do not require SEC approval or compliance with US Generally Accepted Accounting Principles (GAAP). ADRs trading on the NASDAQ market are Levels II and III.

8. There may be selection bias in our sample as the majority of the ADRs trade either on the OTC and the Portal (under Rule 144A). The reason is the majority of the ADRs that trade on major U.S. exchanges (NYSE, Amex and NASDAQ) are either IPOs or with very 
Daily trading volume and closing prices in the domestic markets are collected from the Bridge Data Services. ${ }^{9}$ Official trading hours of the home country stock exchanges are obtained from the 1994 Handbook of World Stock and Commodity Exchanges, and Directory of World Stock Exchanges compiled by the Economist Publications.

\section{Analyses and Results}

The names of companies in the sample, their countries of origin, and U.S. exchanges where the ADRs trade are presented in Appendix A. ${ }^{10}$ The appendix also reports the following statistics before and after ADR listing: the number of trading days, the percent of trading days with zero volume, average number of shares traded daily, and average volatility of daily returns. The ADR listing day and two trading days before and after the listing day are excluded from all analyses. The number of trading days in the overall sample average 253 and 420 before and after the ADR listing, respectively. The percent of days with zero volume average $13.459 \%$ and $8.531 \%$ before and after ADR listing, respectively. The number of trading days with zero volume decreased after ADR listing for 112 of the 153 companies in the sample. This suggests increase in trading activity after ADR listing.

\section{A. Trading Volume Changes Around ADR Listing}

If $V_{i, 1}$ and $V_{i, 2}$ represent average daily trading volume before and after ADR listing, respectively, for company $i$, then volume ratio $\Lambda i=\left(V_{i, 2}\right.$ $\left./ V_{i, 1}\right)$, is greater than 1 if trading volume increases after ADR listing. We use t-statistics to test if the cross-sectional average of $\Lambda i$ is significantly different from one for samples of firms categorized by emerging and developed markets, as well as by the U.S. stock exchange where the ADR is listed (NYSE, NASDAQ, OTC, or 144A).

Average daily trading volume by country are presented in table 1 . 109 of the 153 stocks experience increase in average daily trading volume. The average volume ratios for the entire sample of 153 stocks

limited trading in their home country markets before listing in the US.

9. We are grateful to Bank of New York for allowing us access to this data source.

10. Appendix A is available from the authors upon request. 


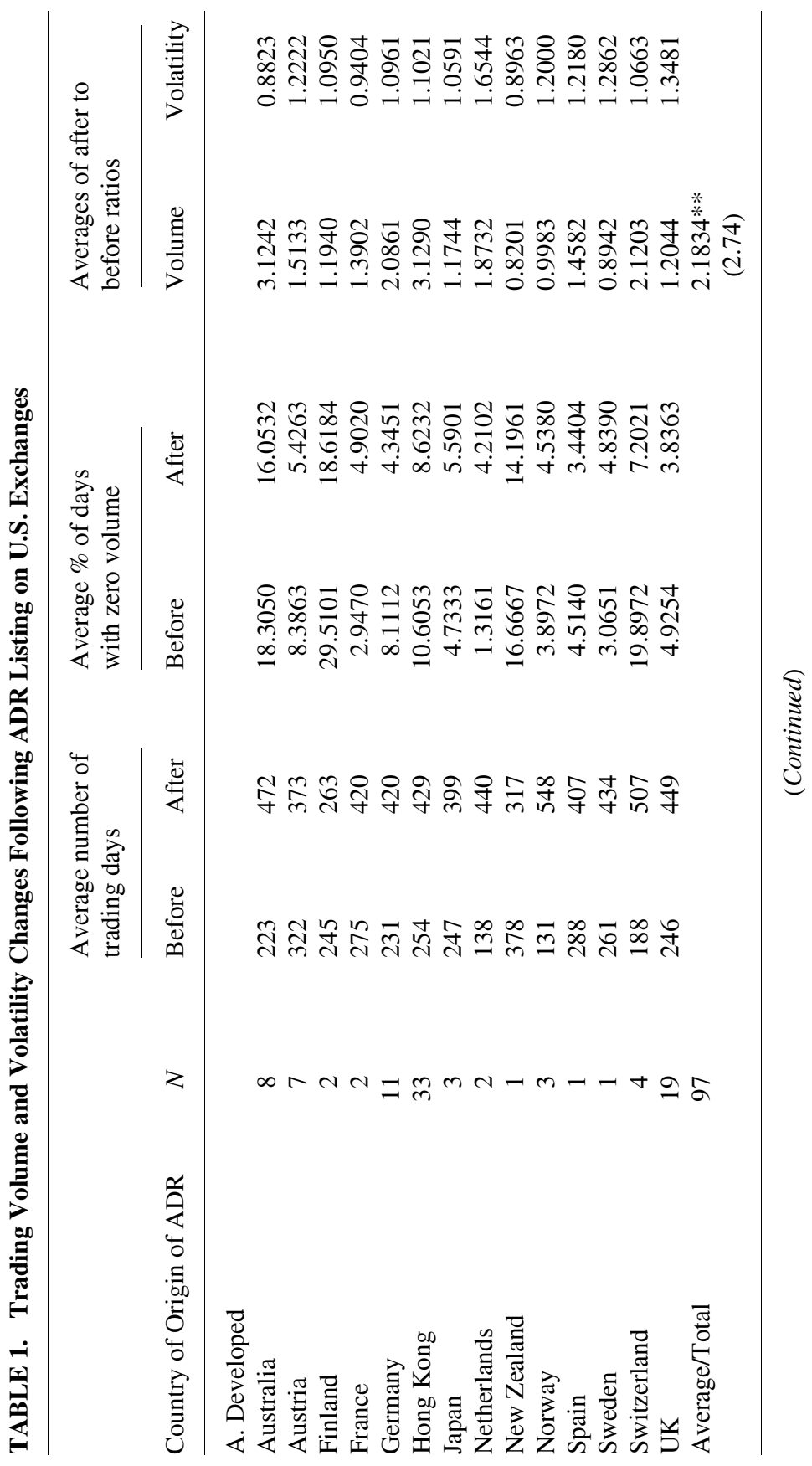




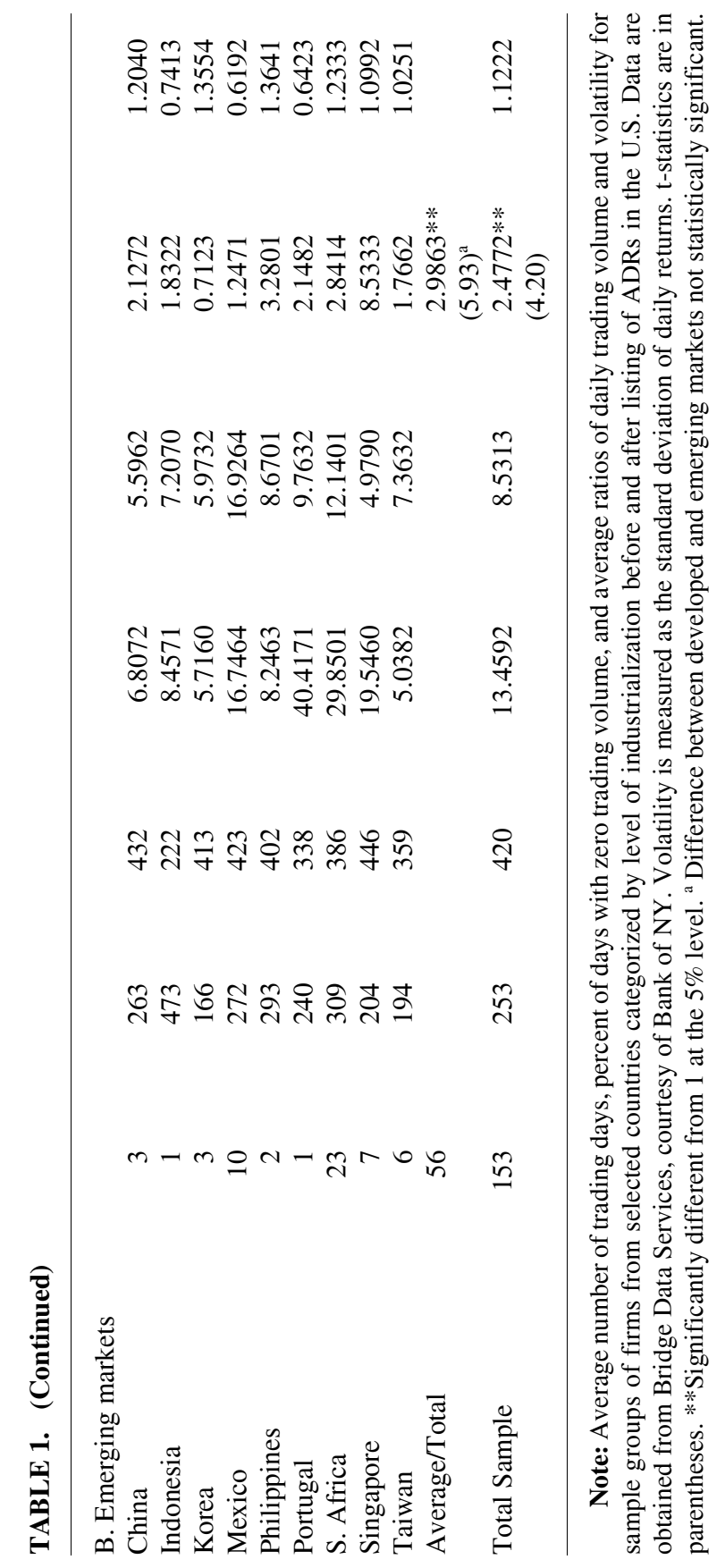


is 2.48 , which is significantly greater than 1 at $5 \%$ level. The highest average trading volume ratio of 8.53 is for Singapore whose ADRs trade on the OTC market. This is largely attributable to SingaporeTelecom experiencing a 44-fold increase in trading volume after ADR listing. Excluding this stock, the average volume ratio for Singapore is 2.6, which is lower than the average for several other countries. Greenfield Coal Ltd. of Australia whose ADR also trades on the OTC market experiences the second largest relative gain in volume. Its post-ADR-listing average daily trading volume is over 17 times higher than the pre-ADR level.

Average daily trading volume decreases for New Zealand, Norway, Sweden, and Korea, however. ${ }^{11}$ The average volume ratios for the rest of the countries are greater than 1, although some of their stocks experience decreases in trading volume after ADR listing. For example, trading volume decreases for five of the 33 stocks from Hong Kong, and for four of the 8 Australian stocks.

The mean volume ratios for developed and emerging market stocks, as well as the entire sample are significantly greater than 1 . The mean volume ratio for emerging market stocks is greater than that for developed market stocks, but the difference is not statistically significant. Some patterns can be discerned from the distribution of volume ratios for European and Asian countries among the developed nations. For most of the European countries, the volume ratios are close to 1 . In contrast, the ratio is well above 1 for Australia and Hong Kong, but it is close to 1 for Japan. Among the emerging countries, Korea and Mexico have the smallest volume ratios. In general, ADRs from countries with whom the U.S. has strong relations and where markets are relatively more informationally efficient register smaller gains in trading volume following ADR listing. This is inconsistent with the evidence in DGM, and Hargis.

\section{B. Analysis of Volatility Changes}

If $\sigma_{i, 1}^{2}$ and $\sigma_{i, 2}^{2}$ represent variance of daily returns for stock $i$ before and after ADR listing, then $\varphi_{i}=\sigma_{i, 2}^{2} / \sigma_{i, 1}^{2}$ is an $F$ distribution with $N_{2}-1$ and $N_{1}-1$ degrees of freedom, where $N_{1}$ and $N_{2}$ are the number of trading days in the sample before and after ADR listing. The change in

11. New Zealand and Sweden have one stock each. For Norway and Korea, trading volume increases for two of the three stocks in the respective samples, although the average volume of the three stocks is lower after ADR listing. 
volatility for each stock and the percentage of stocks for which volatility changes significantly following ADR listing are examined. The magnitude and direction of the change in volatility across firms from emerging and developed markets, and between exchange listed, OTC, and 144A ADRs are also explored.

The last two columns of table 1 report volatility ratios before and after ADR listing for groups of stocks from each country categorized as developed or emerging nation. Volatility ratio of each stock is reported in appendix A. Average volatility increases in 93 (significantly in 69) of the 153 stocks, and decreases in 60 (significantly in 44) of them. The average of volatility ratios for the entire sample is 1.12 , implying an average $12 \%$ increase in volatility after ADR listing. The largest volatility ratio is 2.85 for Yorkshire Food Group of UK, which trades in the OTC market. The smallest volatility ratio is 0.37 for FEMSA Fomento Economico Mexicano of Mexico, which trades on the Portal. Average volatility decreases for six countries (Australia, France, New Zealand, Indonesia, Mexico, and Portugal).

Table 2 presents a contingency table of changes in trading volume and volatility for developed and emerging countries. The significance for the difference between the actual (or observed) and expected frequencies is tested using the chi-square statistic. The proportion of stocks for which trading volume increases after ADR listing is significantly greater than expected under equally likely scenarios for both developed and emerging markets, as well as for the combined sample. 71\% (69/97) of developed country stocks and 71\% (40/56) of emerging market stocks experience increase in trading volume. As such, there is no difference between these markets insofar as the proportion of stock for which trading volume increases following ADR listing.

For change in volatility ratio, the results indicate that for developed countries and the total sample, the proportion of stocks with increase in volatility is significantly greater than what can be expected under equally likely scenario. For the emerging market stocks, the proportion of stocks with increase or decrease in volatility is not significantly different from the expected level. Overall, volatility increases for $61 \%$ of the stocks.

\section{Analysis by Exchange}

Table 3 reports averages of trading volume and volatility ratios by the U.S. exchanges where the ADRs are trading. It is instructive to recall at this point that for ADRs, the OTC market represents trading on pink sheets for mostly Level I ADRs, while the NASDAQ is the dealer market 


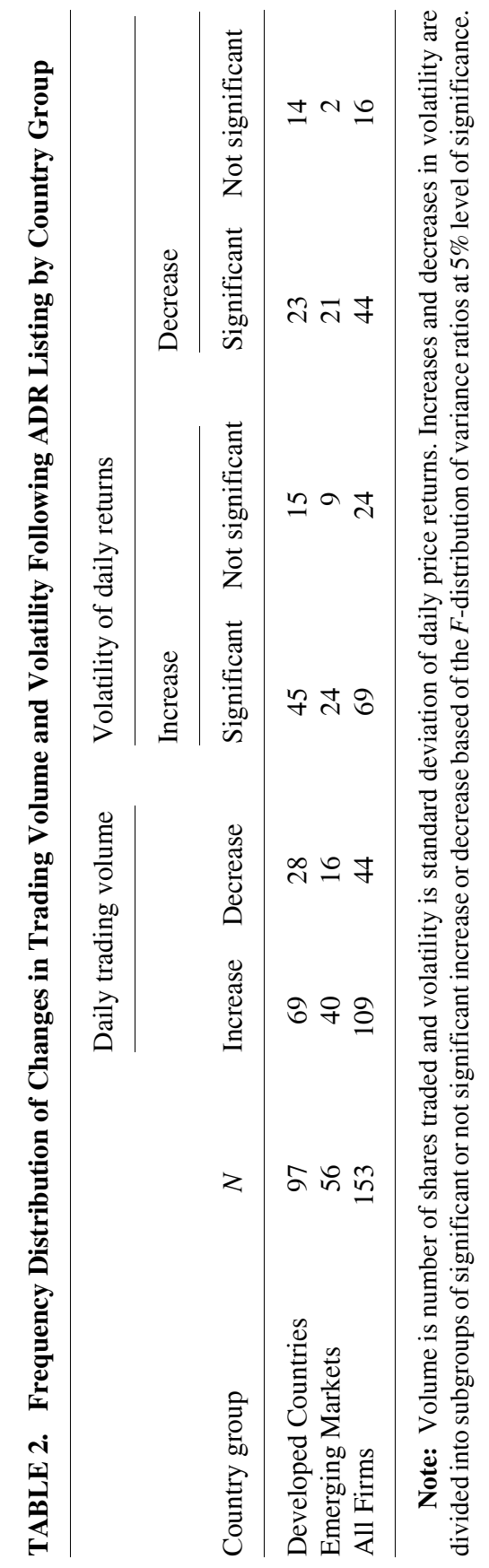


TABLE 3. Difference of Means Tests of Changes in Trading Volume and Volatility Following ADR Listing by U.S. Exchange

\begin{tabular}{lcclcc}
\hline & NYSE & NASDAQ & OTC & $144 \mathrm{~A}$ & All Firms \\
\hline$N$ & 12 & 12 & 103 & 26 & 153 \\
Mean volume ratio & 1.1722 & $1.9483^{*}$ a & $2.8554^{*}$ & $1.8263^{*}$ & $\begin{array}{l}2.4772 * \\
\text { Mean volatility ratio }\end{array}$ \\
\hline
\end{tabular}

Note: Volume ratio is the ratio of average daily number of shares traded after ADR listing to that before ADR listing. Volatility ratio represents the ratio of standard deviation of daily returns after ADR listing to before ADR listing.. *Significantly greater than 1 at 5\% level. ${ }^{\text {a }}$ This mean volume is significantly different from that for the NYSE at the $5 \%$ level.

for trading mostly Levels II and III ADRs. The mean volume ratios are significantly greater than 1 for all exchanges except NYSE. The highest volume ratio of 2.85 is OTC ADRs, followed by 1.95 for NASDAQ, 1.83 for Rule 144A, and 1.17 for NYSE ADRs. Pair-wise comparison of the mean volume ratios by exchanges indicates that only the difference between the mean ratios of NYSE and NASDAQ stocks is statistically significant at $5 \%$ level. A potential explanation is that relatively more trading activity shifted from domestic markets to the U.S. market for NYSE listed ADRs. This is consistent with NYSE's superior liquidity to OTC and NASDAQ markets. Analyses of volatility ratios by groups of stocks based on the U.S. exchanges show that the largest average volatility ratio is for stocks whose ADRs trade in the NASDAQ, followed by those trading on the OTC. None of these volatility ratios except those for NASDAQ ADRs is statistically different from one, and there is no significant difference between any pair of ratios.

Table 4 shows the contingency table of changes in trading volume and volatility of daily returns by U.S. exchanges. Assuming increases and decreases in trading volume to be equally likely, the proportion of stocks which experience increase in trading volume is significantly greater than $50 \%$ for the entire sample and for groups of NYSE, NASDAQ and OTC stocks. There is no significant difference in the frequency of relative increase in trading volume across U.S. exchanges, however.

In terms of frequencies of changes in volatility ratios, 8 of 12 NYSE stocks experience increase in volatility (6 significantly), while volatility ratio decreases significantly in 2 cases. For NASDAQ listed ADRs volatility increases for eight (significantly in seven) stocks, and decreases in four (significantly in 2). For OTC listed ADRs volatility increases in 62 (significantly in 44), and decreases in 41 (significantly 


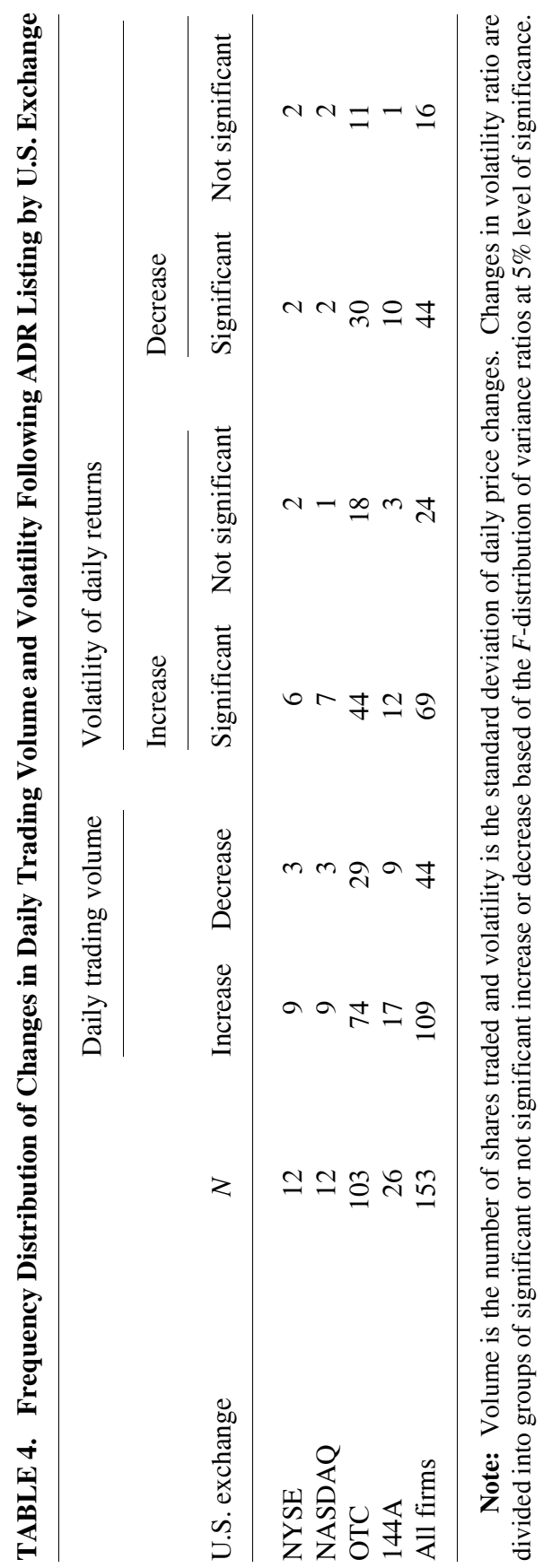


in 30) of the 103 stocks in the sample. Out of the 26 stocks trading on the Portal (Rule 144A), volatility increases significantly in 12 and decreases significantly in 10 of them. The difference between the proportion of actual and expected frequency is significant for the OTC stocks and the combined sample.

In sum, the above analyses indicate that:

1. Average daily trading volume increases in the home market after ADR listing for a significant majority of stocks. Firms from emerging countries show greater gains in trading volume than those from developed countries, but the difference is not significant. Similarly OTC stocks show largest volume gains.

2. Similarly, average volatility of daily returns increases for most of the stocks following ADR listing on U.S. exchanges. Further, increase in volatility is larger for developed market stocks than emerging market stocks, although the difference is not significant. And, the number of stocks with increase in volatility following ADR listing is significantly greater than expected for OTC listed ADRs than for those listed on NYSE, NASD or Rule 144A.

\section{Cross-Sectional Analysis of Changes in Volume and Volatility}

To determine the differential impact of the country of origin and U.S. exchange on the changes in trading volume and volatility following ADR listing, the following multivariate cross-sectional regression equations are estimated:

$$
\begin{gathered}
\left(\Lambda_{i}-1\right)=\alpha_{0}+\alpha_{1} \text { HR }_{i}+\alpha_{2} \text { Dev }_{i}+\alpha_{3} \text { OTC }_{i}+\alpha_{4} \text { Portal }_{i}+\varepsilon_{i} \\
\Delta \sigma_{i}=\beta_{0}+\beta_{1} H_{i}+\beta_{2} \text { Dev }_{i}+\beta_{3} \text { OTC }_{i}+\beta_{4} \text { Portal }_{i}+\beta_{5} e_{i}+v_{i}
\end{gathered}
$$

$\left(\Lambda_{i}-1\right)$ is the percentage change in average daily trading volume, $\Delta \sigma_{i}$, is the percentage change in standard deviation of daily returns (which is equal to square root of $\varphi_{i}$ minus 1). $D e v_{i}$ is a dummy variable with a value of 1 for developed countries, and 0 otherwise; $O T C_{i}$ is a dummy variable with a value of 1 if the ADR is trading in the OTC market and 0 otherwise; and, Portal $_{i}$ is a dummy variable with a value of 1 if the ADR is trading on the Portal (Rule 144A ADR) and 0 otherwise. The 
residual from equation 1 , captures the association between change in volatility due to change in trading volume. $\left(\Lambda_{i}-1\right)$ is not used in equation 2 to avoid multicollinearity because in equation $1,\left(\Lambda_{i}-1\right)$ depends on the same set of variables as $\Delta \sigma_{i}$ in equation 2.

Pulatkonak and Sofianos (1999) argue that distance from the NY Time zone, the time zone effect, is the most important country specific factor. In their data, time zone explains 40 percent of the variation in the U.S. market share with proximity to NY, all else equal, increasing U.S. market share. Following them, the model includes Hri, which represents increase in relative trading hours for the stock after ADR listing. HRi is measured as the increase in trading time in hours as a result of listing ADRs divided by the total trading time in hours in home country. For example, Korean stock market is open during 9:40-11:40 a.m. and 13:20-15:20 p.m. local time (4 hours of trading). Time difference between Korea and NY city is 14 hours, and there is no overlap in the opening trading hours of the two markets. So Korean stocks get additional trading of $61 / 2$ hours after ADR listing. So the relative increase in trading hours is $6.5 / 4=1.625$.

Equation (1) is estimated first, to generate the residuals $\varepsilon_{i}$. Both equations are next estimated simultaneously using the Seemingly Unrelated Regression (SUR) model. $\alpha_{1}$ and $\beta_{1}$ are expected to have positive signs because increase in trading hours increases both trading volume and volatility. Consistent with this, Makhija and Nachtmann (1990) find increase in variance for U.S. stocks after cross-listing on Tokyo Stock Exchange. They attribute the increase in variance to increase in the flow of private information due to increase in trading time. According to DGM, if there is perfect quotation transparency between the U.S. market and the foreign market, ADR listing encourages competition between the markets, improves the precision of price quotations, increases liquidity, and reduces volatility. If this is true, and if there is a higher degree of inter-market linkage between the U.S. market and developed markets than between the U.S. market and emerging markets [Harvey (1995)], $\alpha_{2}$ is expected to be positive while $\beta_{2}$ is expected to be negative. $\beta_{5}$ is expected to be positive because increase in trading volume increases volatility. Under the premise that OTC and Portal markets are considered less liquid than NYSE and NASDAQ, the coefficients $\alpha_{3}$ and $\alpha_{4}$ are expected to be negative in the volume equation 1 , and $\beta_{3}$ and $\beta_{4}$ are expected to be positive in the volatility equation 2 .

The regression estimates of equations 1 and 2 are contained in table 5. In the trading volume equation, only the coefficient for developed 
TABLE 5. Heteroskedasticity Corrected Cross-Sectional Regression Estimates of Trading Volume and Volatility of Returns Equations

\begin{tabular}{lcc}
\hline Variable & $\begin{array}{c}\text { Regression estimates } \\
\text { for the }\left(\Lambda_{i}-1\right) \text { equation }\end{array}$ & $\begin{array}{l}\text { Regression estimates } \\
\text { for the } \Delta \sigma_{i} \text { equation }\end{array}$ \\
\hline HRI & 0.5091 & 0.0422 \\
Dev & $(0.5872)$ & $(0.0562)$ \\
& $-1.4813^{*}$ & 0.0421 \\
OTC & $(0.8032)$ & $(0.0763)$ \\
Portal & 0.9350 & -0.1122 \\
& $(0.9813)$ & $(0.0932)$ \\
$e$ & -0.9011 & -0.1412 \\
Constant & $(1.3223)$ & $-0.1265)$ \\
& & $(0.0060)$ \\
$R$-squared & 1.2871 & 0.1411 \\
$N$ & $(1.0923)$ & $(0.1043)$ \\
& 0.0392 & 0.0243 \\
\hline
\end{tabular}

Note: The regression equations for trading volume and volatility of returns are:

$$
\begin{gathered}
\left(\Lambda_{i}-1\right)=\alpha_{0}+\alpha_{1} \text { HR }_{i}+\alpha_{2} \text { Dev }_{i}+\alpha_{3} \text { OTC }_{i}+\alpha_{4} \text { Portal }_{i}+\varepsilon_{i} \\
\Delta \sigma_{i}=\beta_{0}+\beta_{1} \text { HR }_{i}+\beta_{2} \text { Dev }_{i}+\beta_{3} \text { OTC }_{i}+\beta_{4} \text { Portal }_{i}+\beta_{5} e_{i}+u_{i},
\end{gathered}
$$

where $\left(\Lambda_{i}-1\right)$ and $\Delta \sigma_{i}$ are the percentage change in average daily trading volume and percentage change in standard deviation of daily price returns for stock $i, H R_{i}$ is increase in trading hours for the stock after ADR listing relative to the length of trading hours before ADR listing, Dev is a dummy variable with a value of 1 for developed country stock, and 0 otherwise, $O T C_{i}$ is a dummy variable with a value of 1 if the ADR is trading in the OTC market and 0 otherwise, Portal $_{i}$ is a dummy variable with a value of 1 if the ADR is trading on the Portal (Rule 144A ADR) and 0 otherwise, and $e_{i}$ is the residuals from the volatility of returns regression equation. $e_{i}$ captures the dependence of changes in volatility on changes in volume. Standard errors are given in parentheses. *significant at the $10 \%$ level.

country dummy is statistically significant. The negative sign of the coefficient implies that emerging market stocks gain more in trading volume than developed market stocks. Consistent with our hypothesis, the coefficients representing relative increase in trading time are positive in both equations, but they are statistically insignificant. The coefficient of OTC dummy is positive in the volume equation and negative in the volatility equation, but both are insignificant. This implies that volume increases and volatility decreases for OTC listed ADRs relatively more than for NYSE and NASD listed ADRs. The 


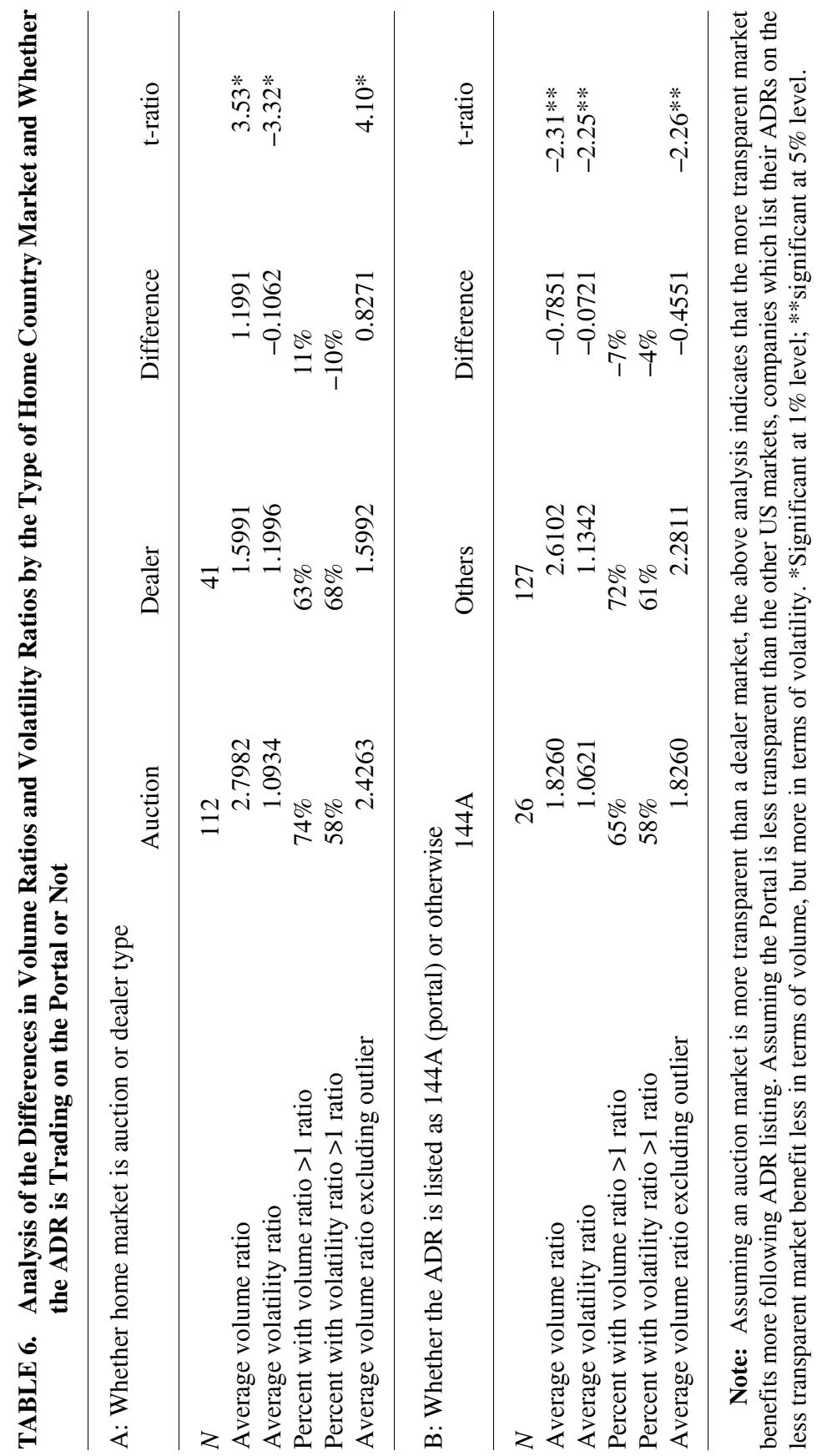


coefficients of the Portal dummy are negative, but statistically insignificant in both equations. The coefficient of the volume proxy in the volatility equation is negative and insignificant.

Table 6 presents the same analyses of volume and volatility changes from the point of view of degree of market openness. Panel A classifies the home country markets as auction or dealer type. 112 of the 153 stocks $(73 \%)$ trade in auction type market while the remaining 41 stocks' (27\%) home country markets are dealer type. For both market types average trading volume ratios have increased after ADR listing and the increase for auction type markets is significantly (at 1\%) greater than the increase for dealer type market. Volatilities, however, increase significantly more for the dealer type market over the auction type. The difference in average volatility ratios is statistically significant at $1 \%$ level. Assuming auction markets are more open than dealer markets, these results are consistent with DGM and Hargis (1996). Companies whose home market is more open benefit more in terms of increased trading activity and improved liquidity following ADR listing.

Panel B of table 6 presents the same analyses based on whether the ADR is listed on the Portal (Rule 144A) or other markets. 26 of 153 stocks (17\%) trade as portal, under rule 144A. Only qualified institutional buyers trade on the portal. Therefore, it is plausible to assume that the portal is less open than the other exchanges. Both average volume ratios and volatility ratios are significantly less for the stocks whose ADRs are listed on the Portal than the others. This implies that companies that list their ADRs on a more transparent U.S. market benefit more in terms of trading volume gain but less in terms of volatility compared to companies that list their ADRs on less transparent U.S. market.

\section{GMM Estimation of DGM Model}

In this section, the generalized method of moments (GMM) is used to test the implications of DGM's model. In the DGM model, volatility is decomposed into base level volatility, which captures bid-ask bounce and uncertainty about price information, and volatility due to trading friction, which is a function of market liquidity. Increase in number of traders reduces both components of volatility. Following DGM, we use the square of daily price change as a proxy for volatility to estimate the following model: ${ }^{12}$

12. An alternative proxy for daily price volatility is the square of the residual in the regression of price on its lag. This has its root in the Rational Expectations Hypothesis of Lucas and Sargent (1981). Price deviation unexplained by its lag is assumed to result from error in public information and trading friction (the same interpretation as DGM's). 


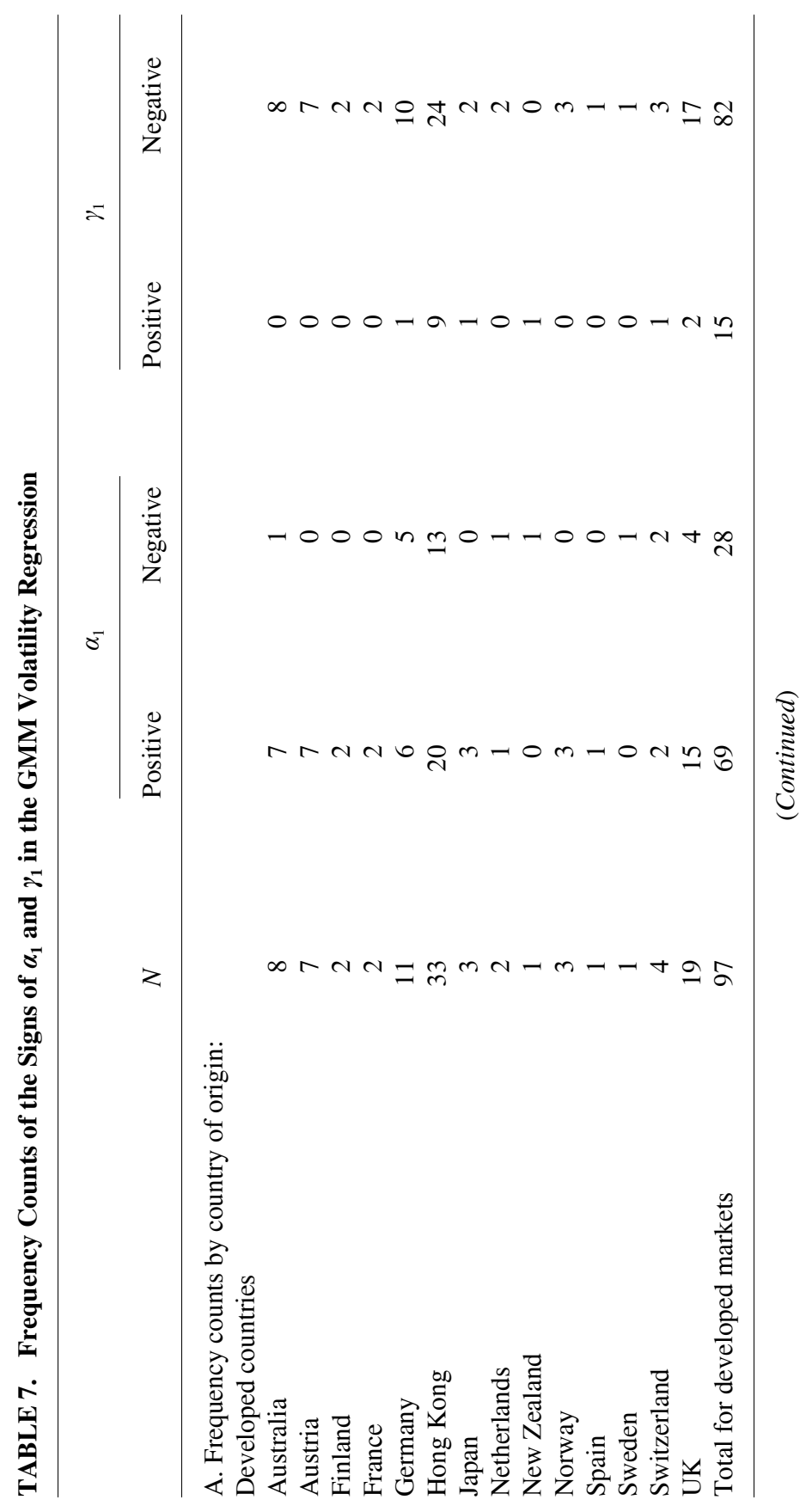




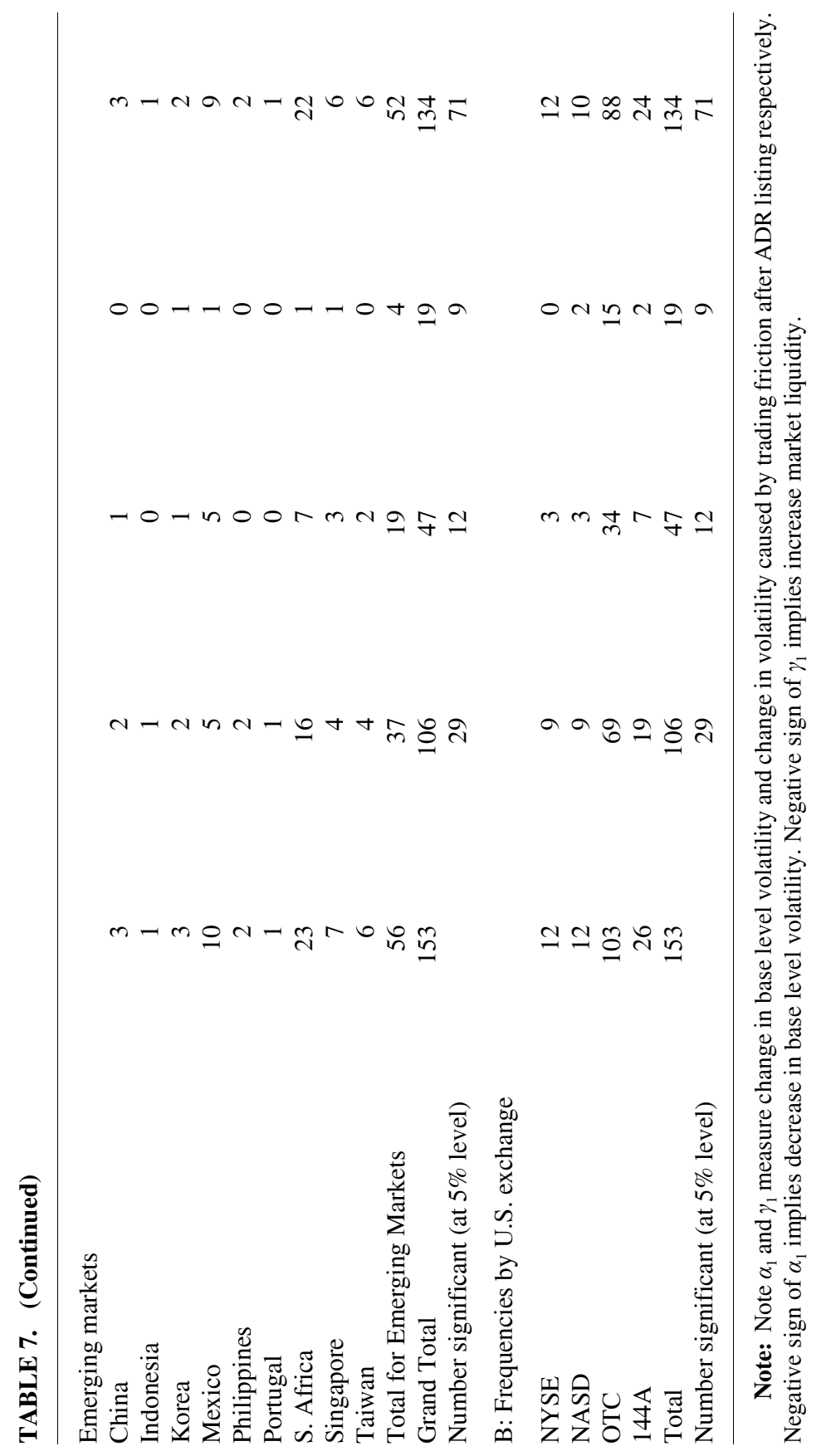




$$
\begin{gathered}
\sigma_{t}^{2}=\alpha_{t}+\beta_{t} \sigma_{t-1}^{2}+\gamma_{t} V_{t}+\varepsilon_{t}, \\
\alpha_{t}=\alpha_{0}+\alpha_{1} A D R_{t} \\
\beta_{t}=\beta_{0}+\beta_{1} A D R_{t} \\
\gamma_{t}=\gamma_{0}+\gamma_{1} A D R_{t}
\end{gathered}
$$

$\sigma_{t}^{2}$ and $\sigma_{t-1}^{2}$ represent average daily volatility and its lag. $V_{t}$ is average daily trading volume. $A D R_{t}$ is a dummy variable with a value of 1 for the period after ADR listing and 0 for the period before. $\mathcal{E}_{t}$ is error term. $\alpha_{0}$ captures the effect of base level volatility caused by error in public information and bounce in bid-ask spread, and $\alpha_{1}$ represents change in this coefficient caused by ADR listing. $\beta_{0}$ measures the relationship between current volatility and its lagged values, and $\beta_{1}$ measures change in this relationship after ADR listing. $\gamma_{0}$ measures volatility caused by trading friction, and $\gamma_{1}$ measures the change in the strength of such association after ADR listing.

According to DGM, under perfect quotation transparency between the U.S. market and the domestic market, ADR listing increases total number of traders and reduces base level volatility. Accordingly, $\alpha_{1}$ is predicted to have a negative sign. Defining market liquidity as inverse of the price impact of a given order imbalance, DGM demonstrate that volatility caused by trading friction depends on trading volume through a factor which is a decreasing function of market liquidity. So increase in $\gamma_{0}$ or a positive $\gamma_{1}$ represents a decrease in liquidity, and a negative $\gamma_{1}$ indicates improvement in liquidity. If ADR listing induces an increase in trading volume, and decrease in bid-ask spread, such that liquidity improves, then $\gamma_{1}$ is predicted to have a negative sign. Finally, under the premise that fundamental (or, base-level) volatility may be related to the price movements on the previous day, $\beta_{0}$ is expected to be positive.

The results of GMM estimation of equation 3 show that $\alpha_{0}$ is positive for 108 of the 153 stocks (71\%), and $\gamma_{0}$ is positive for 141 of the 153 stocks $(92 \%) .{ }^{13}$ This is consistent with the notion that volatility has two components: base level volatility caused by inaccuracy of public information and bid-ask bounce, and volatility caused by trading friction. $\beta_{0}$, which measures the relationship between current volatility

13. A table that lists the coefficient estimates of equation 3 for each of the 153 stocks in the sample is excluded for the sake of brevity. It can be obtained as an appendix from the authors on request. 
and its lag, is negative for $107(70 \%)$ of the stocks, but only six of the stocks have significant coefficients. $\beta_{1}$, which measures change in the relationship between volatility and its lag after ADR listing is positive for 118 of the 153 stocks (77\%), but most of them are statistically insignificant. These results are somewhat at odds with DGM, who report positive coefficient in twenty-one of twenty-five cases, and no appreciable change after ADR listing.

The most critical coefficients in the model are $\alpha_{1}$ and $\gamma 1 . \alpha_{1}$ measures if there is any improvement in the dissemination of public information after ADR listing. The results show that base level volatility increase following ADR listing in 106 (significantly in 29) of the 153 stocks $(69 \%)$ and decreases in $47(31 \%$, significantly in 12) of them. This result is similar to DGM's findings, who report increase in base level volatility for 21 of the 25 stocks in their sample. $\gamma_{1}$ measures change in volatility caused by trading friction and hence it is a proxy for change in liquidity induced by ADR listing. Liquidity improves (i.e., $\gamma_{1}$ is negative) for 134 (significantly for 71) of the 153 (88\%) stocks in the sample, and liquidity decreases in 19 (significantly in 9) of them. This is a stronger result than DGM, who report improvement in liquidity for 11 of the 25 stocks (44\%) in their sample (but the change is not significant for any of them), and decrease in liquidity in 14 of them (significantly in 7 cases).

Table 7, panel A summarizes the analysis by country of origin. Base level volatility decreases in 28 of 97 (29\%) of the developed country stocks. In contrast, it decreases in 19 of 56 (34\%) of emerging market stocks. Liquidity improves in $82(85 \%$, significantly in 49$)$ of the 97 developed country stocks, and in 52 (93\%, significantly in 22) of the 56 emerging market stocks. Although the difference is not significant, emerging market stocks benefit more from ADR listing than developed market stocks in terms of improvement in base level volatility and liquidity. ${ }^{14}$

Comparison across the U.S. exchanges (table 7, panel B) shows that $\alpha_{1}$ is negative (signifying decrease in base level volatility) for 3 of the 12

14. When the countries are grouped by geographical location, the frequency comparison shows that about $93 \%$ of European stocks have negative $\gamma_{1}$ compared to about $81 \%$ of Asian, Australian and New Zealand stocks. But in the case of $\alpha_{1}$, only $26 \%$ of European stocks have negative sign compared to $33 \%$ for Asian, Australian and New Zealand stocks. The differences between these proportions are not statistically significant, but the results indicate that European stocks gained relatively better in terms of reduction of volatility caused by trading friction while Asian, Australian and New Zealand stocks gained relatively better in terms of reduction of base level volatility. 
NYSE stocks (25\%), 3 of the 12 NASD stocks (25\%), 34 of the 103 OTC stocks (33\%), and 7 of the 26 Rule 144A stocks (27\%). These proportions are not significantly different from each other. For $\gamma_{1}$, analysis of observations by exchanges demonstrates NYSE ranks first in terms of improvement in liquidity followed by Rule 144A, OTC and NASD ADRs, respectively. But the differences are not statistically significant.

\section{Summary and Conclusion}

This paper analyzes the impact of ADR listing on the trading volume and volatility of the underlying stock in the domestic market. Average daily trading volume increases for a significant majority of the stocks after ADR listing. Indeed, average daily trading volume more than doubled for the stocks in the overall sample. Comparison of emerging market and developed market samples indicates that although the differences are not statistically significant, emerging market stocks gain relatively more than developed market stocks in terms of both magnitude of increase in trading volume and proportion of stocks for which volume increased. Grouping the stocks based on the U.S. exchange where their ADRs trade indicates that increase in average daily trading volume is the highest for OTC listed stocks followed by NASD and then Rule 144A. For these three groups the average daily trading volume after ADR listing is significantly greater than that before ADR listing. For NYSE listed ADRs the average ratio is greater than 1, but not significantly so. There is no significant difference among the four exchange groups in terms of the magnitude of increase in trading volume and the proportion of the stocks for which trading volume increased.

When the sample is grouped based on whether the home country market is auction or dealer type, the analysis indicates that trading volume increases significantly more for auction type market than for dealer type market.

Similarly, volatility increased on the average for the stocks in the overall sample as well as for the sub-groups, but the change is not significant in most instances. There is no significant difference between volatility changes after ADR listing between developed and emerging country stocks, or the listing exchange. But increase in volatility is significantly more for dealer type home market than for their auction counterpart. 
Next, volatility is decomposed into two main components: base level volatility caused by bid-ask bounce and error in public information, and volatility caused by trading friction. For both of these components, the relationship between change in volatility and trading volume around ADR listing is examined. The analyses show that base level volatility increased for most of the stocks. Volatility caused by trading friction decreases for majority of the stocks in the sample, which indicates an improvement in market liquidity after ADR listing. Finally, the proportion of stocks for which liquidity improves is not significantly different across sample groups although emerging market stocks gain relatively more than developed market stocks. The evidence that emerging market stocks gain relatively more than their developed country counterparts in terms of liquidity does not support the contention that developed country markets and U.S. markets have greater linkages than emerging markets and U.S. markets.

Overall, ADR listing does not retard the home country market; it rather increases its trading volume and improves its liquidity. These improvements are positively related to the degree of market openness (transparency) of the home country.

\section{References}

Bloomfield, R. and O'Hara, M. 2000. Can transparent markets survive? Journal of Financial Economics (March): 425-459.

Domowitz, I.; Glen, J.; and Madhavan, A. 1998. International cross-listing and order flow migration: Evidence from an emerging market. Journal of Finance (December): 2001-2027.

Freund, J.E. 1971. Mathematical Statistics. 2nd ed. New Jersey: Prentice-Hall.

Goldberg, C.S. and Delgado, F.A. 2001. Financial integration of emerging markets: An analysis of Latin America versus South Asia using individual stocks. Multinational Finance Journal 5: 259-301.

Hargis, K. 1996. ADRs in Emerging equity markets: market competition or fragmentation. Working Paper: University of South Carolina.

Harvey, C. R. 1995. Predictable risk and returns in emerging markets. Review of Financial Studies (Fall): 773-816.

Hertzel. M.; Lowengrub, P.; and Melvin, M. 2000. Information, announcement, and listing effects of ADR programs and German-U.S. Stock market integration. Multinational Finance Journal 4: 181-200.

Levine, R., and Zervos, S. 1996. Capital control liberalization and stock market development. Working Paper: World Bank Policy Research (Mimeographed). 
Lucas, R. E. Jr., and Sargent, T J. 1981. Rational expectations and econometric practice. Minneapolis: University of Minnesota Press.

Makhija, A.K. and Nachtmann, R. 1990. Variance effects of cross-listing of NYSE stocks in Tokyo. In S.G. Rhee and R.P. Chang (eds). Pacific-Basin Capital Markets Research 215-226.

McNemar, Q. 1969. Psychological Statistics, 4th Ed. NY: Wiley.

Mendehall, W.; Wackerly, D.D.; and Scheaffer, R.L. 1990. Mathematical Statistics with Applications. 4th ed, PWS-Kent Publishing Company.

Merton, R.C. 1987. A simple model of capital market equilibrium with incomplete information. Journal of Finance (July): 483-510.

Miller, D. P. 1999. The market reaction to international cross-listings: Evidence from depositary receipts. Journal of Financial Economics (January): 103-123.

Niarchos, N.; Tse, Y.; Wu, C.; and Young, A. 1999. International transmission of information: A study of the relationship between the U.S. and Greek stock markets. Multinational Finance Journal 3: 19-40.

O'Hara, M. 1999. Making market microstructure matter. Financial Management (Summer): 83-90.

Pagano, M. 1989. Trading volume and asset liquidity. Quarterly Journal of Economics (May): 255-274.

Pulatkonak, M. and Sofianos, G. 1999. The distribution of global trading in NYSE-listed non-U.S. stocks. Working Paper 99-03, NYSE.

Siegel, S. 1956. Nonparametric Statistics for the Behavioral Sciences. NY: McGraw-Hill. 